\title{
Long term outcomes in men screened for abdominal aortic aneurysm: prospective cohort study
}

\author{
@ @Q $\Theta$ OPEN ACCESS
}

\author{
John L Duncan consultant ${ }^{1}$, Kirsten A Harrild research fellow ${ }^{2}$, Lisa Iversen research fellow ${ }^{3}$, Amanda \\ $\mathrm{J}_{\mathrm{Lee}}$ professor $^{2}$, David J Godden professor ${ }^{4}$
}

${ }^{1}$ Department of Surgery, Raigmore Hospital, Inverness IV2 3UJ, UK; ${ }^{2}$ Medical Statistics Team, Division of Applied Health Sciences, University of Aberdeen, Aberdeen, UK; ${ }^{3}$ Academic Primary Care, Division of Applied Health Sciences, University of Aberdeen; ${ }^{4}$ Centre for Rural Health, University of Aberdeen, Centre for Health Sciences, Inverness

\begin{abstract}
Objective To determine whether there is a relation between aortic diameter and morbidity and mortality in men screened for abdominal aortic aneurysm.

Design Prospective cohort study.

Setting Highland and Western Isles (a large, sparsely populated area of Scotland).

Participants 8146 men aged 65-74.

Main outcome measures Morbidity and mortality in relation to presence of abdominal aortic aneurysm and three categories of aortic diameter ( $\leq 24 \mathrm{~mm}, 25-29 \mathrm{~mm}$, and $\geq 30 \mathrm{~mm}$ ).

Results When screened, 414 men (5.1\%) had an aneurysm (diameter $\geq 30 \mathrm{~mm}), 669$ (8.2\%) an aortic diameter of $25-29 \mathrm{~mm}$, and $7063(86.7 \%)$ an aortic diameter of $\leq 24 \mathrm{~mm}$. The cohort was followed up for a median of 7.4 (interquartile range 6.9-8.2) years. Mortality was significantly associated with aortic diameter: $512(7.2 \%)$ men in the $\leq 24 \mathrm{~mm}$ group died compared with 69 (10.3\%) in the $25-29 \mathrm{~mm}$ group and $73(17.6 \%)$ in the $\geq 30 \mathrm{~mm}$ group. The mortality risk in men with an aneurysm or with an aorta measuring 25-29 mm was significantly higher than in men with an aorta of $\leq 24 \mathrm{~mm}$. The increased mortality risk in the $25-29 \mathrm{~mm}$ group was reduced when taking confounders such as smoking and known heart disease into account. After adjustment, compared with men with an aortic diameter of $\leq 24 \mathrm{~mm}$, the risk of hospital admission for cardiovascular disease and chronic obstructive pulmonary disease was significantly higher in men with aneurysm and those with aortas measuring 25-29 mm. Men with an aneurysm also had an increased risk of hospital admission for cerebrovascular disease, atherosclerosis, peripheral arterial disease, and respiratory disease. In men with aortas measuring 25-29 mm, the risk of hospital admission with abdominal aortic aneurysm was significantly higher than in men with an aorta of $\leq 24 \mathrm{~mm}$ (adjusted hazard ratio 6.7, 99\% confidence interval 3.4 to 13.2) and this increased risk became apparent two years after screening.
\end{abstract}

Conclusions Men with abdominal aortic aneurysm and those with aortic diameters measuring 25-29 mm have an increased risk of mortality and subsequent hospital admissions compared with men with an aorta diameter of $\leq 24 \mathrm{~mm}$. Consideration should be given to control of risk factors and to rescreening men with aortas measuring $25-29 \mathrm{~mm}$ at index scanning.

\section{Introduction}

Screening for abdominal aortic aneurysm in men over 65 years of age has been recommended on the basis of several randomised controlled trials and meta-analyses. ${ }^{12}$ These studies have shown that a single screening examination using ultrasound with follow-up intervention as appropriate can reduce aneurysm related mortality, with benefits extending to at least 10 years. ${ }^{3}$ Screening has been shown to be cost effective ${ }^{4}$ and has already been, or is being, introduced in the United Kingdom. ${ }^{56}$ Patients with an abdominal aortic aneurysm, however, have also been shown to have an increased mortality from other vascular disease, ${ }^{478}$ which in some part may be responsible for the failure of screening for abdominal aortic aneurysm to reduce all cause mortality in most studies.

Most screening protocols use a threshold aortic diameter of 30 $\mathrm{mm}$. Men with an aorta at or above this diameter are entered into a follow-up programme and those below are reassured and no follow-up planned. Among those without an aneurysm, however, there is some evidence of a possible association between aortic diameter and mortality, raising the possibility of a significantly increased risk among those whose aortic diameter is just below the threshold for aneurysm. ${ }^{9}$

We used record linkage to investigate the health outcomes of a group of 8146 men who attended the Highland aortic aneurysm screening programme between 2001 and 2004 and were followed until mid 2010, and to determine how these outcomes related 
to aortic diameter. We examined morbidity and mortality for men who had an aortic aneurysm (aortic diameter $\geq 30 \mathrm{~mm}$ ), and those who had an ectatic aorta $(25-29 \mathrm{~mm})$ compared with those whose aorta was $\leq 24 \mathrm{~mm}$ at initial screening.

\section{Methods}

Between April 2001 and March 2004 we invited men in Highland and Western Isles aged 65-74 to attend the Highland aortic aneurysm screening programme. At the time of the initial scan, men completed a questionnaire about their general health and provided personal details. The programme's dataset contains age at screening, self rated assessment of health, smoking history (in pack years), medical history, family history of cardiovascular disease and diabetes, place of birth, postcode, duration of time living in the region, and the outcome of the abdominal aortic aneurysm screening.

The aortic diameter was defined as the maximum antero-posterior diameter, measured to the nearest millimetre. Failure to image in the community was followed through with hospital based ultrasound. We defined abdominal aortic aneurysm as an aorta measuring $30 \mathrm{~mm}$ or more; men with aortas of this size were followed up using the protocol from the Multicentre Aneurysm Screening Study. ${ }^{10}$ Men with abdominal aortic aneurysms measuring 30-44 mm were rescanned annually and those with aortas measuring 45-54 $\mathrm{mm}$ were rescanned every three months. Men with aneurysms measuring $55 \mathrm{~mm}$ or more were considered for surgery. Men with aneurysms were offered lifestyle advice, and correspondence to their general practitioner suggested treatment with aspirin and a statin. Those men with a "normal" scan (aortic diameter $\leq 29 \mathrm{~mm}$ ) had no further intervention or screening.

By linking the questionnaire data from the Highland aortic aneurysm screening programme to the Scottish Morbidity Record linked dataset held by the Information Services Division at the Scottish government health department we obtained longer term outcomes (aneurysm related morbidity and mortality in relation to aortic diameter at screening). Using probability matching, the Information Services Division linked the Highland aortic aneurysm screening programme dataset to the national Scottish Morbidity Record database (comprised of general acute inpatient and day case discharges SMR01, cancer registrations SMR06, and the General Registrar Office-Scotland death registrations) and provided an anonymous linked dataset for analysis. Appendix 1 shows the outcome codes (international classification of diseases, ninth and 10th revisions). Deprivation was expressed in fifths and 10ths according to the Scottish index of multiple deprivation, ${ }^{11}$ and rurality by the Scottish government urban-rural classification $^{12}$; both were derived from postcodes.

We obtained descriptive statistics for the cohort as a whole and categorised participants by their baseline aortic diameter into three groups: $\leq 24 \mathrm{~mm}, 25-29 \mathrm{~mm}$, and $\geq 30 \mathrm{~mm}$. To compare categorical variables between the three groups we used $\chi^{2}$ tests for trend, with analysis of variance and the Kruskal-Wallis tests used to compare normally and non-normally distributed data across the groups.

The end of follow-up was 26 June 2010. Cox proportional hazards regression was used to calculate crude hazard ratios ( $99 \%$ confidence intervals) for events of interest. We compared each of the $25-29 \mathrm{~mm}$ and $30 \mathrm{~mm}$ or more groups with the 24 $\mathrm{mm}$ or less group. Subsequently we simultaneously adjusted the estimates for a range of personal characteristics, indicators of medical history, and markers of general health. The potential covariates included those identified from a review of published literature, together with those deemed clinically important when examining the association between aortic diameter and morbidity and mortality. Into the models we entered the number of pack years smoked, with a value of zero for non-smokers, and deprivation 10th, rather than fifth, but otherwise the variables remained in their original format (categorical or continuous). Smoking status was the only variable that was initially considered for entry into the models but not subsequently used, owing to collinearity with pack years. To avoid competing risks, in the survival analyses of each non-fatal event of interest we excluded those men who had had one of the other listed non-fatal events. The models for mortality included all the men. For the hospital admission outcomes we produced separate

Kaplan-Meier survival curves for each aortic diameter group. Tests for interactions between deprivation 10th and aortic diameter group were done for all hospital admission outcomes. For those outcomes with a test for interaction $\mathrm{P}<0.10$, we carried out further survival analyses stratified by deprivation fifth.

The proportion of missing values among the personal and health related factors was low $(<9 \%)$ and seemed to be missing at random. Therefore we excluded missing values from the analysis. Owing to multiple outcomes, we regarded a more stringent $P$ value of $\leq 0.01$ as statistically significant for the main analyses. All analyses were carried out using the software package PASW Statistics 18.0.2 (SPSS, Chicago, IL).

\section{Results}

Of the 8355 men who attended for screening, ${ }^{13} 8146(97.5 \%)$ completed the questionnaire and so were available for record linkage. The uptake of screening in the original cohort was $89.6 \%$ (3.8\% declined an appointment and 6.6\% did not attend). The figure of 8146 therefore represents $86 \%$ of the men aged 65-74 living in the region between 2001 and 2004. The median duration of follow-up was 7.4 (interquartile range 6.9-8.2) years. Of the 8146 men, $414(5.1 \%$ ) had an aortic aneurysm (aortic diameter $\geq 30 \mathrm{~mm}), 669(8.2 \%)$ had an aortic diameter 25-29 $\mathrm{mm}$, and $7063(86.7 \%)$ a diameter of $24 \mathrm{~mm}$ or less. Table $1 \Downarrow$ shows the personal and health related data obtained from the questionnaire. A larger aortic diameter at screening was associated with older age (although the differences in age were small); current smoking; higher pack years (among ever smokers); poorer self assessed health; reported previous heart attack, hypertension, or stroke; and a family history of aneurysm.

Of the 8146 men, 654 (8.0\%) died within the follow-up period. Table $2 \Downarrow$ shows the primary cause of death. Mortality was associated with aortic diameter at screening: 512 (7.2\%) men with an aortic diameter of $24 \mathrm{~mm}$ or less died compared with $69(10.3 \%)$ with a diameter of $25-29 \mathrm{~mm}$ and $73(17.6 \%)$ with a diameter of $30 \mathrm{~mm}$ or more. Aneurysm accounted for only 11 deaths (1.7\% of all deaths). Of the nine aneurysm related deaths in men with an initial aortic diameter of $30 \mathrm{~mm}$ or more, five were caused by ruptured abdominal aortic aneurysm and the rest were postoperative deaths. Deaths in only two men with an aortic diameter less than $30 \mathrm{~mm}$ were attributed to aneurysm during follow-up, neither associated with rupture. Most of the excess mortality risk associated with aortic diameter was due to hypertension and vascular disease or cancer, relations that persisted in the $30 \mathrm{~mm}$ or more group even after adjustment for potential confounders. Men with an aortic diameter of $30 \mathrm{~mm}$ or more were over three times as likely to die from cancer (adjusted hazard ratio 3.03, 99\% confidence interval 1.41 to $6.53)$ and nearly twice as likely to die from hypertensive and vascular disease (1.90, 1.17 to 3.08$)$ than men with an aortic diameter of $24 \mathrm{~mm}$ or less. 
Aortic diameter at screening was also associated with hospital admissions (table $3 \Downarrow$ ). The proportion of men with no subsequent hospital admission was $34.8 \%(\mathrm{n}=2459)$ in the $24 \mathrm{~mm}$ or less group compared with $29.6 \%(\mathrm{n}=198)$ in the $25-29 \mathrm{~mm}$ group and $16.9 \%(\mathrm{n}=70)$ in the $30 \mathrm{~mm}$ or more group. Increasing aortic diameter at screening was associated with increased subsequent risk of admission for all circulatory disease (table 3 and fig $1 \Downarrow$ ). After adjustment for potential confounders, men with aortic diameters or more than $25 \mathrm{~mm}$ were at increased risk of hypertensive disease, ischaemic heart disease, and chronic obstructive pulmonary disease, whereas the increased risk of cerebrovascular disease, atherosclerosis, peripheral arterial disease, and diseases of the respiratory system was significant only in the $30 \mathrm{~mm}$ or more group. Compared with men with an aortic diameter of $24 \mathrm{~mm}$ or less, those with an aortic diameter of 25-29 mm had an increased risk of diabetes mellitus and of heart failure, but these risks were not found in men with an aneurysm. Lung cancer remained more common in the aneurysm group after adjustment. Men with an aneurysm at screening were over seven times more likely to have abdominal wall hernia or conditions such as intraperitoneal adhesions (table 3 ). Increasing aortic diameter at screening was associated with increasing risk of subsequent admission for aneurysm. For those in the 25-29 mm category, this became evident from two years after screening (fig $2 \Downarrow$ ).

\section{Discussion}

In this study, baseline screening identified $5.1 \%$ of men with an aneurysm $(\geq 30 \mathrm{~mm})$ and $8.2 \%$ with an aortic diameter of 25-29 mm, which has been termed ectatic aorta. A previous study found a prevalence of $7.5 \%$ of ectatic aorta in a similar aged cohort using similar criteria for diameter, but included a distal renal/aortic antero-posterior diameter ratio of more than 1.2 as an alternative definition. ${ }^{14} \mathrm{~A}$ key issue dealt with by our study is whether men with an ectatic aorta have an excess risk of poor outcomes. The mortality rate in our cohort during follow-up was low and deaths due to aneurysm were rare. However, increasing aortic diameter at screening was associated with increased mortality from vascular disease or cancer and increased risk of hospital admissions, mainly related to circulatory and respiratory diseases and certain forms of cancer. The increased morbidity was noted not only in those with aortic aneurysm at initial screening but also in those with ectatic aortas, a small proportion of whom were also discharged from hospital with a diagnosis of aneurysm during follow-up. These relations held after adjustment for several potential confounders.

\section{Comparison with other studies}

Mortality in this cohort- $8 \%$ after a median of 7.4 (interquartile range 6.9-8.2) years follow-up-was low compared with previously published series. In the Multicentre Aneurysm Screening Study cohort, who were of similar age to ours, mortality in the invited group was $11.4 \%$ after a median follow-up of 4.1 years $^{10}$ and total mortality was $30 \%$ at 10 years. ${ }^{3}$ In the Tromso study, ${ }^{15}$ which included a wider age range of men and women (25-84 years), mortality in men at 10 years was $19.9 \%$, and in the American Cardiovascular Health study, which included men and women with an average age of 75 at screening, ${ }^{9}$ mortality at 10 years was $38.6 \%$. The reasons for our lower mortality, apart from differences in age, are unclear, although may reflect improving cardiovascular risk prevention and the relatively rural nature of our cohort. ${ }^{1316}$ The risk of death from aneurysm in our cohort was low. In total, 11 deaths were reported as being due to aneurysm, representing $0.14 \%$ of the cohort and $1.7 \%$ of all deaths. Most of these deaths were in men who had aneurysm at initial screening. Only two deaths occurred among those with an aortic diameter of less than $30 \mathrm{~mm}$, representing $0.03 \%$ of that group. In the Multicentre Aneurysm Screening Study, the death rate from aneurysm at 10 years among those who attended screening was $0.33 \%$ (91/27 201), whereas 19 deaths $(0.08 \%)$ were reported in 25541 men with an index scan showing an aortic diameter of less than $30 \mathrm{~mm}$. The follow-up was 10.1 years, making the risk of a ruptured aneurysm 1:10 216 life years compared with 1:12 454 life years for this study. In the Multicentre Aneurysm Screening Study cohort, however, the rate of rupture increased noticeably in years 8-10 of follow-up. In the Tromso study, ${ }^{15}$ the death rate from aneurysm for the whole cohort at 10 years was $0.41 \%$ $(27 / 6640)$, whereas for those with normal scans it was $0.1 \%$ (7/6295).

Although the risk of aneurysm related mortality is small, previous studies have shown a significant risk of developing an aneurysm in men with an aortic diameter of 25-29 mm. ${ }^{14}{ }^{17}$ One study, in a UK programme, found an expansion rate of $0.9 \mathrm{~mm}$ yearly in men with ectatic aortas, resulting in $2.4 \%$ of these men exceeding an aortic diameter of $55 \mathrm{~mm}$ or requiring surgery within five years of initial screening. ${ }^{17}$ A Danish study found that $29 \%$ of men with an initial aortic diameter of $25-29 \mathrm{~mm}$ went on to develop aneurysms, with expansion rates varying from 1-4.7 mm annually. ${ }^{14}$ Both studies concluded that men with ectatic aortas should be screened every five years. In our study, men whose initial aortic diameter was less than $30 \mathrm{~mm}$ were not rescanned, so we cannot report rates of expansion or the development of aneurysm. However, $4.5 \%$ of men with an aortic diameter of 25-29 $\mathrm{mm}$ had a hospital admission with an aneurysm diagnosis during follow-up, such presentations becoming noticeable from two years after screening, supporting the concept of repeat screening in the $25-29 \mathrm{~mm}$ group. The association between aneurysm and cardiovascular disease that we observed has been shown in several studies. ${ }^{16} 1819$ In the Tromso study, ${ }^{15}$ an abdominal aortic aneurysm at baseline conferred a 2.5 -fold increase in cardiovascular mortality over 10 years, compared with a 1.88 -fold increased risk in our study. One study followed up 4734 men and women aged over 65 for 10 years. ${ }^{9}$ They found an increased risk of mortality associated with aneurysm, but the increased risk of cardiovascular events in men with aortic diameters of 20-29 mm did not reach statistical significance. However, the criteria for a diagnosis of abdominal aortic aneurysm and the follow-up periods differed between the studies. The UK Small Aneurysm Trial also showed that aortic aneurysm was a marker for cardiovascular disease, with increased cardiovascular mortality not related to aneurysm. $^{20}$

Men with abdominal aortic aneurysm therefore have an increased risk of cardiovascular disease, suggesting that secondary prevention interventions for cardiovascular disease are appropriate. Men with an aortic diameter of 25-29 $\mathrm{mm}$ have an increased risk of cardiovascular disease, which disappears when confounders such as smoking, deprivation, and hypertension are taken into account. The Tromso study compared participants with an aortic diameter of 27-29 mm with a reference group measuring 21-23 mm and found a twofold increase in cardiovascular mortality in the higher diameter group. ${ }^{15}$ In our study, the increased risk of mortality from all causes for the 25-29 mm category became non-significant after adjustment for confounding variables, perhaps reflecting the differing diameter criteria used. However, there was a significantly increased risk of subsequent hospital admission due to hypertensive and ischaemic heart disease, heart failure, 
diabetes mellitus, and chronic obstructive pulmonary disease. It could be argued that interventions known to reduce the impact of these factors, such as smoking cessation, antihypertensive treatment, statins, and aspirin, might reduce that risk.

Screening for abdominal aortic aneurysm is being implemented throughout the United Kingdom. According to current proposed protocols, men with an aortic diameter less than $30 \mathrm{~mm}$ would receive no further intervention and no follow-up screening. In the Tromso study, it was recommended that those participants with an aortic diameter greater than $27 \mathrm{~mm}$ should be followed up for subsequent development of an aneurysm and for cardiovascular risk reduction, although specifics of a follow-up regimen were not given. ${ }^{15}$ Another study was even more tentative, concluding that it remains unclear whether screening for abdominal aortic aneurysm could be used to identify people at risk of cardiovascular disease. ${ }^{9}$

\section{Strengths and weaknesses of the study}

Our study has several strengths. The cohort comprised $86 \%$ of men aged 65-74 in Highland and Western Isles at the time of enrolment. We obtained outcome data by linking to national hospital admissions and cancer and death registrations, with no loss to follow-up. Data were available on a wide range of potential confounders, including smoking, health status, family medical history, and socioeconomic status, enabling these to be taken into account. An obvious limitation is that no women were included in the cohort. Most screening programmes for aortic aneurysm to date have not included women as they are less likely to have aortic aneurysm ${ }^{21}$ and are likely to have them later in life than men. ${ }^{22}$ Furthermore, although the cohort was large, relatively few men died, so the study may have lacked power to detect differences for some of the specific causes of mortality.

\section{Conclusions and policy implications}

In conclusion, men can benefit from undergoing abdominal aortic aneurysm screening. The problem that remains for men with an enlarged, but non-aneurysmal aorta, is whether they should be rescreened and whether they should be offered interventions aimed at reducing their cardiovascular risk.

Contributors: JLD, LI, AJL, and DJG designed the study. KAH did the analysis. All authors interpreted the data and were involved in drafting the manuscript. JLD is the guarantor.

Funding: The project was funded by a grant from the Chief Scientist Office, Scotland (CZG/2/485). The funder had no role in the study design; the collection, analysis, and interpretation of data; the writing of the article; or the decision to submit the article for publication.

Competing interests: All authors have completed the ICMJE uniform disclosure form at www.icmje.org/coi_disclosure.pdf (available on request from the corresponding author) and declare: no support from any organisation for the submitted work other than the grant award; no financial relationships with any organisations that might have an interest in the submitted work in the previous three years; no other relationships or activities that could appear to have influenced the submitted work.

Ethical approval: This study was approved by the Scottish Government Privacy Advisory Committee and the relevant Caldicott Guardian.

Data sharing: No additional data available.

1 Lindholt JS, Norman PE. Meta-analysis of postoperative mortality after elective repair of abdominal aortic aneurysms detected by screening. Br J Surg 2011;98:619-22.

2 Takagi H, Goto SN, Matsui M, Manabe H, Umemoto T. A further meta-analysis of population-based screening for abdominal aortic aneurysm. J Vasc Surg 2010;52:1103-8.

3 Thompson SG, Ashton HA, Gao L, Scott RA. Screening men for abdominal aortic aneurysm: 10 year mortality and cost effectiveness results from the randomised Multicentre Aneurysm Screening Study. BMJ 2009;338:b2307.

4 Multicentre Aneurysm Screening Study Group. Multicentre aneurysm screening study (MASS): cost effectiveness analysis of screening for abdominal aortic aneurysms based on four year results from randomised controlled trial. BMJ 2002;325:1135.

5 NHS Abdominal Aortic Aneurysm Screening Programme. Annual report. 2012. http://aaa. screening.nhs.uk/annual_report.

6 The Scottish Government. Scottish abdominal aortic aneurysm screening programme. 2010. www.sehd.scot.nhs.uk/mels/CEL2010_11.pdf.

7 Brady AR, Fowkes FG, Thompson SG, Powell JT. Aortic aneurysm diameter and risk of cardiovascular mortality. Arterioscler Thromb Vasc Biol 2001;21:1203-7.

8 Lindholt JS. Relatively high pulmonary and cardiovascular mortality rates in screening-detected aneurysmal patients without previous hospital admissions. Eur $J$ Vasc Endovasc Surg 2007;33:94-9.

9 Freiberg MS, Arnold AM, Newman AB, Edwards MS, Kraemer KL, Kuller LH. Abdominal aortic aneurysms, increasing infrarenal aortic diameter, and risk of total mortality and incident cardiovascular disease events: 10-year follow-up data from the Cardiovascular Health Study. Circulation 2008;117:1010-7.

10 Ashton HA, Buxton MJ, Day NE, Kim LG, Marteau TM, Scott RA, et al. The Multicentre Aneurysm Screening Study (MASS) into the effect of abdominal aortic aneurysm screening on mortality in men: a randomised controlled trial. Lancet 2002;360:1531-9.

11 The Scottish Government. Scottish Government urban rural classification. 2008. www. scotland.gov.uk/Publications/2008/07/29152642/0.

12 The Scottish Government. Scottish index of multiple deprivation. 2004. www.scotland. gov.uk/Publications/2005/01/20458/49127.

13 Duncan JL, Wolf B, Nichols DM, Lindsay SM, Cairns J, Godden DJ. Screening for abdominal aortic aneurysm in a geographically isolated area. Br J Surg 2005;92:984-8.

14 Lindholt JS, Vammen S, Juul S, Fasting H, Henneberg EW. Optimal interval screening and surveillance of abdominal aortic aneurysms. Eur J Vasc Endovasc Surg 2000;20:369-73.

15 Forsdahl SH, Singh K, Solberg S, Jacobsen BK. Risk factors for abdominal aortic aneurysms: a 7-year prospective study: the Tromso Study, 1994-2001. Circulation 2009;119:2202-8.

16 Lindsay SM, Duncan JL, Cairns J, Godden DJ. Geography, private costs and uptake of screening for abdominal aortic aneurysm in a remote rural area. BMC Public Health 2006;6:80.

17 McCarthy RJ, Shaw E, Whyman MR, Earnshaw JJ, Poskitt KR, Heather BP. Recommendations for screening intervals for small aortic aneurysms. Br J Surg 2003;90:821-6.

18 Reed D, Reed C, Stemmermann G, Hayashi T. Are aortic aneurysms caused by atherosclerosis? Circulation 1992;85:205-11.

19 Newman AB, Arnold AM, Burke GL, O'Leary DH, Manolio TA. Cardiovascular disease and mortality in older adults with small aortic aneurysms detected by ultrasonography: the cardiovascular health study. Ann Intern Med 2001;134:182-90.

20 Powell JT, Brown LC, Forbes JF, Fowkes FG, Greenhalgh RM, Ruckley CV, et al. Final 12-year follow-up of surgery versus surveillance in the UK Small Aneurysm Trial. Br J Surg 2007;94:702-8.

21 Scott RAP, Vardulaki KA, Walker NM, Day NE, Duffy SW, Ashton HA. The long-term benefits of a single scan for abdominal aortic aneurysm (AAA) at age 65. Eur $J$ Vasc Endovasc Surg 2001;21:535-40.

22 Cosford PA, Leng GC, Thomas J. Screening for abdominal aortic aneurysm. Cochrane Database Syst Rev 2007;2:CD002945.

Accepted: 20 March 2012

\section{Cite this as: BMJ 2012;344:e2958}

This is an open-access article distributed under the terms of the Creative Commons Attribution Non-commercial License, which permits use, distribution, and reproduction in any medium, provided the original work is properly cited, the use is non commercial and is otherwise in compliance with the license. See: http://creativecommons.org/licenses/bync/2.0/ and http://creativecommons.org/licenses/by-nc/2.0/legalcode. 


\section{What is already known on this topic}

Screening for abdominal aortic aneurysm is effective in reducing aneurysm related mortality

Men with an aneurysm have a higher mortality from other vascular diseases than men without an aneurysm

\section{What this study adds}

Men with an ectatic aorta $(25-29 \mathrm{~mm})$ at time of screening for abdominal aortic aneurysm have a significantly higher risk of mortality and of admission to hospital than men with a normal sized aorta $(\leq 24 \mathrm{~mm})$

The increased risk of death was associated with higher rates of circulatory disease

The increased risk of admission to hospital was due to circulatory disease and chronic obstructive pulmonary disease

\section{Tables}

Table 1| Baseline personal and health related characteristics of all men by aortic diameter group. Values are numbers (percentages) of participants unless stated otherwise

\begin{tabular}{|c|c|c|c|c|c|}
\hline \multirow[b]{2}{*}{ Characteristic } & \multicolumn{3}{|c|}{ Aortic diameter $(\mathrm{mm})$} & \multirow[b]{2}{*}{ Total $(n=8146)$} & \multirow[b]{2}{*}{$P$ value } \\
\hline & $\leq 24(n=7063)$ & $25-29(n=669)$ & $\geq 30(n=414)$ & & \\
\hline Mean (SD) age (years) & $70.3(2.9)$ & $70.6(2.9)$ & $70.8(2.8)$ & $70.3(2.9)$ & $<0.001$ \\
\hline \multicolumn{6}{|l|}{ Place of birth: } \\
\hline Western Isles & $745(10.5)$ & $69(10.3)$ & $50(12.1)$ & $864(10.6)$ & \multirow[t]{6}{*}{0.760} \\
\hline Highland & $2957(41.9)$ & $295(44.1)$ & $179(43.2)$ & $3431(42.1)$ & \\
\hline Rest of Scotland & $1944(27.5)$ & $184(27.5)$ & $107(25.8)$ & $2235(27.4)$ & \\
\hline Rest of United Kingdom & $1182(16.7)$ & $100(14.9)$ & $60(14.5)$ & $1342(16.5)$ & \\
\hline Other & $192(2.7)$ & $15(2.2)$ & $12(2.9)$ & $219(2.7)$ & \\
\hline Missing & $43(0.6)$ & $6(0.9)$ & $6(1.4)$ & $55(0.7)$ & \\
\hline \multicolumn{6}{|l|}{ Years lived in Highland: } \\
\hline Median (interquartile range) & $50(26-69)$ & $55(27-70)$ & $55(27-70)$ & $50(26-69)$ & \multirow[t]{2}{*}{0.078} \\
\hline Missing & $221(3.1)$ & $23(3.4)$ & $14(3.4)$ & $258(3.2)$ & \\
\hline \multicolumn{6}{|l|}{ Deprivation fifth*: } \\
\hline 1 (most deprived) & $221(3.1)$ & $24(3.6)$ & $5(1.2)$ & $250(3.1)$ & \multirow[t]{6}{*}{0.183} \\
\hline 2 & $1650(23.4)$ & $153(22.9)$ & $105(25.4)$ & $1908(23.4)$ & \\
\hline 3 & $2532(35.8)$ & $269(40.2)$ & $147(35.5)$ & $2948(36.2)$ & \\
\hline 4 & $1543(21.8)$ & $138(20.6)$ & $94(22.7)$ & $1775(21.8)$ & \\
\hline 5 (least deprived) & $614(8.7)$ & $49(7.3)$ & $21(5.1)$ & $684(8.4)$ & \\
\hline Missing & $503(7.1)$ & $36(5.4)$ & $42(10.1)$ & $581(7.1)$ & \\
\hline \multicolumn{6}{|l|}{ Urban-rural status $\uparrow:$} \\
\hline Other urban areas & $1224(17.3)$ & $84(12.6)$ & $63(15.2)$ & $1371(16.8)$ & \multirow[t]{5}{*}{$<0.001$} \\
\hline Accessible small towns and rural & $1144(16.2)$ & $92(13.8)$ & $58(14.0)$ & $1294(15.9)$ & \\
\hline Remote small towns and rural & $1030(14.6)$ & $81(12.1)$ & $60(14.5)$ & $1171(14.4)$ & \\
\hline Very remote small towns and rural & $3169(44.9)$ & $377(56.4)$ & $191(46.1)$ & $3737(45.9)$ & \\
\hline Missing & $496(7.0)$ & $35(5.2)$ & $42(10.1)$ & $573(7.0)$ & \\
\hline \multicolumn{6}{|l|}{ Smoking status: } \\
\hline Never smoked & $2283(32.3)$ & $145(21.7)$ & $59(14.3)$ & $2487(30.5)$ & \multirow[t]{3}{*}{$<0.001$} \\
\hline Former smoker & $3562(50.4)$ & $356(53.2)$ & $224(54.1)$ & $4142(50.8)$ & \\
\hline Current smoker & $1218(17.2)$ & $168(25.1)$ & $131(31.6)$ & $1517(18.6)$ & \\
\hline Median No (interquartile range) pack years $\ddagger$ & $24(12-40)$ & $30(18-50)$ & $36(20-50)$ & $25(13-40)$ & $<0.001$ \\
\hline \multicolumn{6}{|l|}{ General health: } \\
\hline Excellent & $906(12.8)$ & $73(10.9)$ & $26(6.3)$ & 1005 (12.3) & \multirow[t]{4}{*}{$<0.001$} \\
\hline Very good & $2595(36.7)$ & $218(32.6)$ & $136(32.9)$ & 2949 (36.2) & \\
\hline Good & $2286(32.4)$ & $231(34.5)$ & $154(37.2)$ & 2671 (32.8) & \\
\hline Fair & $1044(14.8)$ & $118(17.6)$ & $74(17.9)$ & $1236(15.2)$ & \\
\hline
\end{tabular}


Table 1 (continued)

\begin{tabular}{|c|c|c|c|c|c|}
\hline \multirow[b]{2}{*}{ Characteristic } & \multicolumn{3}{|c|}{ Aortic diameter $(\mathrm{mm})$} & \multirow[b]{2}{*}{ Total $(n=8146)$} & \multirow[b]{2}{*}{$P$ value } \\
\hline & $\leq 24(n=7063)$ & $25-29(n=669)$ & $\geq 30(n=414)$ & & \\
\hline Poor & $184(2.6)$ & $21(3.1)$ & $18(4.3)$ & $223(2.7)$ & \\
\hline Missing & $48(0.7)$ & $8(1.2)$ & $6(1.4)$ & $62(0.8)$ & \\
\hline Ever had a heart attack & $927(13.1)$ & $117(17.5)$ & $88(21.3)$ & $1132(13.9)$ & $<0.001$ \\
\hline Ever had high blood pressure & $2672(37.8)$ & $280(41.9)$ & $188(45.4)$ & $3140(38.5)$ & $<0.001$ \\
\hline Ever had a stroke & $382(5.4)$ & $63(9.4)$ & $42(10.1)$ & $487(6.0)$ & $<0.001$ \\
\hline Ever had diabetes & $755(10.7)$ & $98(14.6)$ & $43(10.4)$ & $896(11.0)$ & 0.172 \\
\hline Ever had a different condition & $1791(25.4)$ & $174(26.0)$ & $121(29.2)$ & $2086(25.6)$ & 0.098 \\
\hline \multicolumn{6}{|c|}{ Close relative ever had a heart attack: } \\
\hline Yes & $2306(32.6)$ & $242(36.2)$ & $138(33.3)$ & $2686(33.0)$ & \multirow[t]{3}{*}{0.175} \\
\hline No & $4408(62.4)$ & $399(59.6)$ & $247(59.7)$ & $5054(62.0)$ & \\
\hline Missing & $349(4.9)$ & $28(4.2)$ & $29(7.0)$ & $406(5.0)$ & \\
\hline \multicolumn{6}{|c|}{ Close relative ever had high blood pressure: } \\
\hline Yes & $1543(21.8)$ & $153(22.9)$ & 95 (22.9) & $1791(22.0)$ & \multirow[t]{3}{*}{0.342} \\
\hline No & $5043(71.4)$ & $472(70.6)$ & $282(68.1)$ & $5797(71.2)$ & \\
\hline Missing & $477(6.8)$ & $44(6.6)$ & $37(8.9)$ & $558(6.8)$ & \\
\hline \multicolumn{6}{|l|}{ Close relative ever had a stroke: } \\
\hline Yes & $1378(19.5)$ & $132(19.7)$ & $67(16.2)$ & $1577(19.4)$ & \multirow[t]{3}{*}{0.198} \\
\hline No & $5205(73.7)$ & $496(74.1)$ & $314(75.8)$ & $6015(73.8)$ & \\
\hline Missing & $480(6.8)$ & $41(6.1)$ & $33(8.0)$ & $554(6.8)$ & \\
\hline \multicolumn{6}{|l|}{ Close relative ever had diabetes: } \\
\hline Yes & $882(12.5)$ & $98(14.6)$ & $45(10.9)$ & $1025(12.6)$ & \multirow[t]{3}{*}{0.984} \\
\hline No & $5646(79.9)$ & $530(79.2)$ & $333(80.4)$ & $6509(79.9)$ & \\
\hline Missing & $535(7.6)$ & $41(6.1)$ & $36(8.7)$ & $612(7.5)$ & \\
\hline \multicolumn{6}{|c|}{ Close relative ever had an aortic aneurysm: } \\
\hline Yes & $217(3.1)$ & $25(3.7)$ & $24(5.8)$ & 266 (3.3) & \multirow[t]{3}{*}{0.002} \\
\hline No & $6233(88.2)$ & $593(88.6)$ & 347 (83.8) & $7173(88.1)$ & \\
\hline Missing & $613(8.7)$ & $51(7.6)$ & $43(10.4)$ & 707 (8.7) & \\
\hline
\end{tabular}

*Based on Scottish index of multiple deprivation 2004.

†Based on Scottish Executive eightfold urban-rural classification.

$\ddagger$ Current and former smokers only. 


\begin{tabular}{|c|c|c|c|c|c|c|c|}
\hline \multirow[b]{2}{*}{ Cause of death } & \multicolumn{3}{|c|}{ Aortic diameter $(\mathrm{mm})$} & \multicolumn{2}{|c|}{ Crude hazard ratio $(99 \% \mathrm{Cl})$} & \multicolumn{2}{|c|}{ Adjusted hazard ratio* $(99 \% \mathrm{Cl}$} \\
\hline & $\leq 24(n=7063)$ & $25-29(n=669)$ & $\geq 30(n=414)$ & $25-29 \mathrm{~mm}$ & $\geq 30 \mathrm{~mm}$ & $25-29 \mathrm{~mm}$ & $\geq 30 \mathrm{~mm}$ \\
\hline Cancer & $91(1.3)$ & $9(1.3)$ & $16(3.9)$ & 1.05 (0.43 to 2.59$)$ & $3.02(1.50$ to 6.06$)$ & $\begin{array}{c}0.92(0.33 \text { to } \\
2.57)\end{array}$ & $\begin{array}{c}3.03(1.41 \text { to } \\
6.53)\end{array}$ \\
\hline Diabetes & $10(0.1)$ & $1(0.1)$ & $1(0.2)$ & $\begin{array}{c}1.06(0.07 \text { to } \\
15.75)\end{array}$ & $\begin{array}{c}1.71(0.12 \text { to } \\
25.47)\end{array}$ & - & - \\
\hline $\begin{array}{l}\text { Central nervous system } \\
\text { disease }\end{array}$ & $18(0.3)$ & $2(0.3)$ & $1(0.2)$ & $1.17(0.17$ to 8.00$)$ & $\begin{array}{c}0.95(0.07 \text { to } \\
13.38)\end{array}$ & - & - \\
\hline $\begin{array}{l}\text { Hypertensive and } \\
\text { vascular disease }\end{array}$ & $305(4.3)$ & $50(7.5)$ & $43(10.4)$ & 1.77 (1.20 to 2.63$)$ & 2.49 (1.63 to 3.78$)$ & $\begin{array}{c}1.20(0.75 \text { to } \\
1.94)\end{array}$ & $\begin{array}{c}1.90(1.17 \text { to } \\
3.08)\end{array}$ \\
\hline Aneurysm & $1(<0.1)$ & $1(0.1)$ & $9(2.2)$ & - & - & - & - \\
\hline $\begin{array}{l}\text { Chronic obstructive } \\
\text { pulmonary disease }\end{array}$ & $32(0.5)$ & $3(0.4)$ & $2(0.5)$ & $0.99(0.21$ to 4.70$)$ & 1.06 (0.16 to 6.95$)$ & $\begin{array}{c}1.04(0.21 \text { to } \\
5.10)\end{array}$ & $\begin{array}{c}0.53(0.04 \text { to } \\
7.44)\end{array}$ \\
\hline $\begin{array}{l}\text { Gastrointestinal } \\
\text { disease }\end{array}$ & $15(0.2)$ & $0(0.0)$ & $0(0.0)$ & - & - & - & - \\
\hline $\begin{array}{l}\text { Other external causes, } \\
\text { unintentional injuries, } \\
\text { and suicide }\end{array}$ & $9(0.1)$ & $0(0.0)$ & $1(0.2)$ & - & - & - & - \\
\hline Other & $31(0.4)$ & $3(0.4)$ & $0(0.0)$ & - & - & - & - \\
\hline All causes & $512(7.2)$ & $69(10.3)$ & $73(17.6)$ & 1.46 (1.05 to 2.02$)$ & 2.57 (1.86 to 3.55$)$ & $\begin{array}{c}1.08(0.73 \text { to } \\
1.59)\end{array}$ & $\begin{array}{c}2.03(1.40 \text { to } \\
2.94)\end{array}$ \\
\hline
\end{tabular}


Table 3| Risk of first admission to hospital for specific conditions by aortic diameter group. Values are numbers (percentages) of participants unless stated otherwise

\begin{tabular}{|c|c|c|c|c|c|c|c|}
\hline \multirow{2}{*}{$\begin{array}{l}\text { Discharge } \\
\text { diagnosis }\end{array}$} & \multicolumn{3}{|c|}{ Aortic diameter $(\mathrm{mm})$} & \multicolumn{2}{|c|}{ Crude hazard ratio $(99 \% \mathrm{Cl})$} & \multicolumn{2}{|c|}{ Adjusted hazard ratio* $(99 \% \mathrm{Cl})$} \\
\hline & $\leq 24(n=7063)$ & $25-29(n=669)$ & $\geq 30(n=414)$ & $25-29 \mathrm{~mm}$ & $\geq 30 \mathrm{~mm}$ & $25-29 \mathrm{~mm}$ & $\geq 30 \mathrm{~mm}$ \\
\hline $\begin{array}{l}\text { All circulatory } \\
\text { disease: }\end{array}$ & $3796(53.7)$ & $406(60.7)$ & $329(79.5)$ & $1.24(1.09$ to 1.42$) \dagger$ & $1.92(1.65$ to 2.22$) \dagger$ & $1.20(1.04$ to 1.39$) \dagger$ & $1.51(1.27$ to 1.79$) \dagger$ \\
\hline $\begin{array}{l}\text { Hypertensive } \\
\text { disease }\end{array}$ & $2385(33.8)$ & $270(40.4)$ & $198(47.8)$ & $1.31(1.11$ to 1.54$) \dagger$ & $2.10(1.74$ to 2.55$) \dagger$ & $1.29(1.08$ to 1.54$) \dagger$ & $1.60(1.29$ to 1.99$) \dagger$ \\
\hline $\begin{array}{l}\text { Acute myocardial } \\
\text { infarction }\end{array}$ & $363(5.1)$ & $48(7.2)$ & $35(8.5)$ & $1.60(1.07$ to 2.37$) \dagger$ & $2.91(1.85$ to 4.60$) \dagger$ & $1.43(0.93$ to 2.21$)$ & 1.66 (0.97 to 2.85$)$ \\
\hline $\begin{array}{l}\text { Ischaemic heart } \\
\text { disease }\end{array}$ & $1633(23.1)$ & $201(30.0)$ & $159(38.4)$ & $1.41(1.16$ to 1.71$) \dagger$ & $2.39(1.93$ to 2.96$) \dagger$ & $1.33(1.08$ to 1.64$) \dagger$ & $1.52(1.18$ to 1.94$) \dagger$ \\
\hline Heart failure & $587(8.3)$ & $95(14.2)$ & $46(11.1)$ & 1.85 (1.39 to 2.46$) \dagger$ & 2.40 (1.62 to 3.56$) \dagger$ & 1.55 (1.12 to 2.14$) \dagger$ & 1.25 (0.78 to 2.01$)$ \\
\hline $\begin{array}{l}\text { Cerebral vascular } \\
\text { disease }\end{array}$ & $559(7.9)$ & $76(11.4)$ & $46(11.1)$ & 1.59 (1.16 to $2.18 \dagger)$ & 2.58 (1.74 to 3.83$) \dagger$ & 1.35 (0.95 to 1.91$)$ & $1.58(1.02$ to 2.45$) \dagger$ \\
\hline Atherosclerosis & $51(0.7)$ & $7(1.0)$ & $10(2.4)$ & 1.69 (0.60 to 4.77$)$ & $\begin{array}{c}6.55(2.69 \text { to } \\
15.96) \dagger\end{array}$ & 1.56 (0.50 to 4.86$)$ & $\begin{array}{c}3.84(1.39 \text { to } \\
10.63) \dagger\end{array}$ \\
\hline Aneurysm & $44(0.6)$ & $30(4.5)$ & $263(63.5)$ & $\begin{array}{c}7.92(4.30 \text { to } \\
14.57) \dagger\end{array}$ & $\begin{array}{c}88.82(58.14 \text { to } \\
135.70) \dagger\end{array}$ & $\begin{array}{c}6.75(3.44 \text { to } \\
13.23) \dagger\end{array}$ & $\begin{array}{c}66.67(41.59 \text { to } \\
106.88) \dagger\end{array}$ \\
\hline $\begin{array}{l}\text { Peripheral arterial } \\
\text { disease }\end{array}$ & $350(5.0)$ & $43(6.4)$ & $58(14.0)$ & 1.49 (0.99 to 2.27$)$ & 4.67 (3.24 to 6.73$) \dagger$ & 1.33 (0.84 to 2.09 ) & 2.33 (1.49 to 3.62$) \dagger$ \\
\hline Diabetes mellitus & $829(11.7)$ & $111(16.6)$ & $49(11.8)$ & $1.55(1.19$ to 2.00$) \dagger$ & $1.87(1.28$ to 2.72$) \dagger$ & $1.46(1.10$ to 1.94$) \dagger$ & $1.21(0.79$ to 1.86$)$ \\
\hline $\begin{array}{l}\text { Diseases of the } \\
\text { respiratory system: }\end{array}$ & $1630(23.1)$ & $188(28.1)$ & $131(31.6)$ & 1.33 (1.09 to 1.63$) \dagger$ & $1.98(1.57$ to 2.50$) \dagger$ & 1.21 (0.98 to 1.51$)$ & $1.38(1.05$ to 1.80$) \dagger$ \\
\hline $\begin{array}{l}\text { Chronic obstructive } \\
\text { pulmonary disease }\end{array}$ & $623(8.8)$ & $90(13.5)$ & $73(17.6)$ & $1.68(1.25$ to 2.24$) \dagger$ & $3.13(2.28$ to 4.30$) \dagger$ & $1.47(1.07$ to 2.03$) \dagger$ & $1.98(1.37$ to 2.86$) \dagger$ \\
\hline $\begin{array}{l}\text { Abdominal wall and } \\
\text { peritoneal disease }\end{array}$ & $69(1.0)$ & $12(1.8)$ & $16(3.9)$ & 2.14 (0.96 to 4.79$)$ & $\begin{array}{c}7.41(3.63 \text { to } \\
15.15) \dagger\end{array}$ & 1.71 (0.60 to 4.88$)$ & $\begin{array}{c}7.81 \text { (3.48 to } \\
17.52) \dagger\end{array}$ \\
\hline Neoplasms (all): & $1736(24.6)$ & $169(25.3)$ & $102(24.6)$ & $1.19(0.95$ to 1.48$)$ & 1.71 (1.30 to 2.26$) \dagger$ & $1.17(0.91$ to 1.49$)$ & $1.32(0.96$ to 1.81$)$ \\
\hline Lung & $200(2.8)$ & $20(3.0)$ & $25(6.0)$ & 1.25 (0.67 to 2.32$)$ & $3.92(2.24$ to 6.84$) \dagger$ & $1.29(0.67$ to 2.45$)$ & $2.85(1.50$ to 5.40$) \dagger$ \\
\hline $\begin{array}{l}\text { Digestive organs } \\
\text { and peritoneum }\end{array}$ & $399(5.6)$ & $42(6.3)$ & $27(6.5)$ & 1.32 (0.86 to 2.04$)$ & 2.31 (1.38 to 3.85$) \dagger$ & 1.33 (0.82 to 2.16$)$ & $1.83(1.01$ to 3.32$) \ddagger$ \\
\hline $\begin{array}{l}\text { Large bowel and } \\
\text { rectum }\end{array}$ & $243(3.4)$ & $20(3.0)$ & $11(2.7)$ & $0.97(0.51$ to 1.86$)$ & $1.72(0.78$ to 3.81$)$ & $1.02(0.50$ to 2.11$)$ & 1.56 (0.63 to 3.84$)$ \\
\hline
\end{tabular}

Group with aortic diameter $\leq 24 \mathrm{~mm}$ was reference category for both crude and adjusted hazard ratios.

*Adjusted for age; number of years lived in the Highlands; urban-rural status; number of pack years smoked; deprivation 10th; general health; ever had a heart attack, high blood pressure, stroke, or different condition; and a close relative ever had an aortic aneurysm.

$\dagger P \leq 0.01$.

$\ddagger \mathrm{P} \leq 0.05$. 


\section{Figures}

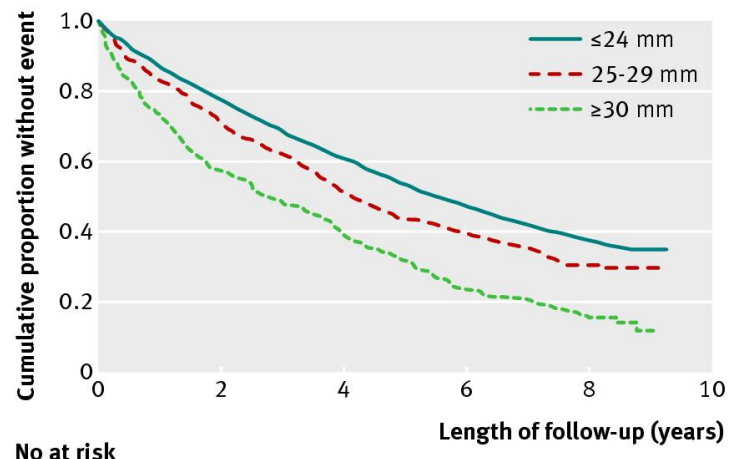

No at risk

$\begin{array}{rcccc}\leq 24 \mathrm{~mm} \\ 6252 & 4831 & 3780 & 2951 & 775 \\ 25-29 \mathrm{~mm} & & & & \\ 604 & 427 & 307 & 239 & 46 \\ \geq 30 \mathrm{~mm} & & & & \\ 398 & 226 & 156 & 93 & 20\end{array}$

Fig 1 Time to hospital admission for all circulatory disease by aortic diameter

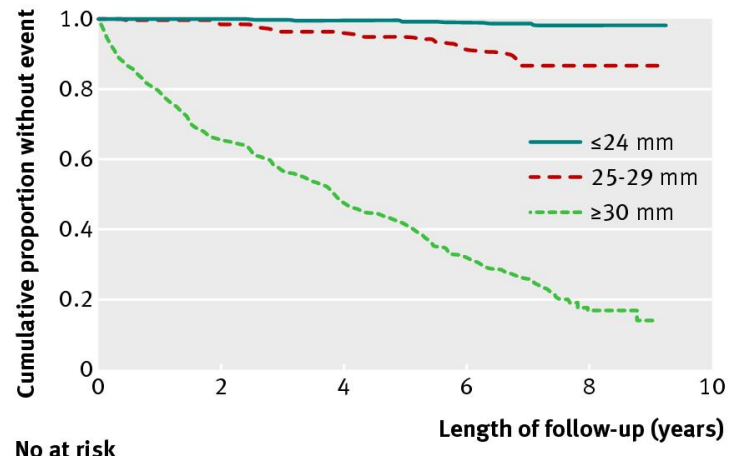

No at risk

$\leq 24 \mathrm{~mm}$

$\begin{array}{rrrrr}2503 & 2498 & 2486 & 2470 & 739 \\ 25-29 \mathrm{~mm} & & & & \\ 228 & 224 & 218 & 208 & 45 \\ \geq 30 \mathrm{~mm} & & & & \\ 332 & 216 & 156 & 106 & 19\end{array}$

Fig 2 Time to hospital admission for aortic aneurysm by aortic diameter 